\title{
pontolinha, linhaponto, linhalinha, planoplano, pontoponto, linhaplano, planolinha, planoponto. matemática e arte e educação.
}

\author{
Sônia Maria Clareto ${ }^{1}$ \\ Fabrício Teixeira Carvalho ${ }^{2}$
}

\begin{abstract}
Resumo: Neste trabalho os autores se lançam a experimentações visuais com objetos e palavras operando com noções elementares de ponto, linha e plano produzindo um ensaio visual composto por uma série de fotografias. As imagens apresentam exercícios de produção de atrito entre matemática, arte e educação a partir de situações em que pequenos objetos dialogam com aquelas noções elementares. A produção visual é acompanhada de notas de leitura de Kandinsky, Euclides e Deleuze \& Guattari, propondo um convite a outras possibilidades.
\end{abstract}

Palavras-chave: Ponto; Linha; Plano.

\section{pointline, linepoint, lineline, planeplane, pointpoint, lineplane, planeline, planepoint. mathematics and art and education.}

\begin{abstract}
In this paper the authors throw a visual experiments with words and objects operating with elementary notions of point, line and plan, producing a visual assay formed by photographs. The images have friction production exercises between mathematics, art and education from situations where small objects dialogue with those elementary notions. The visual production is accompanied by Kandinsky, Deleuze \& Guattari Euclid reading notes and proposing an invitation to other possibilities.
\end{abstract}

Keywords: Point; Line; Plan.

1 Doutora em Educação Matemática pela UNESP Campus de Rio Claro. Atua como docente da Universidade Federal de Juiz de Fora (MG) junto ao Departamento de Educação e junto ao Programa de Pós-graduação em Educação, nos níveis de mestrado e doutorado. Líder do Travessia Grupo de Pesquisa, cadastrado na Plataforma de Grupos do CNPq. E-mail: sclareto@yahoo.com.

2 Mestre em Artes Visuais pela UFRJ, atua como artista desde 2003, tornando-se professor junto ao Instituto de Artes e Design da Universidade Federal de Juiz de Fora (MG) a partir de 2010. Também na UFJF formou-se em bacharelado e licenciatura em Artes e no momento é doutorando em Educação. E-mail: fabriciotcarvalho@hotmail.com. Site: www.fabriciocarvalho.net. 


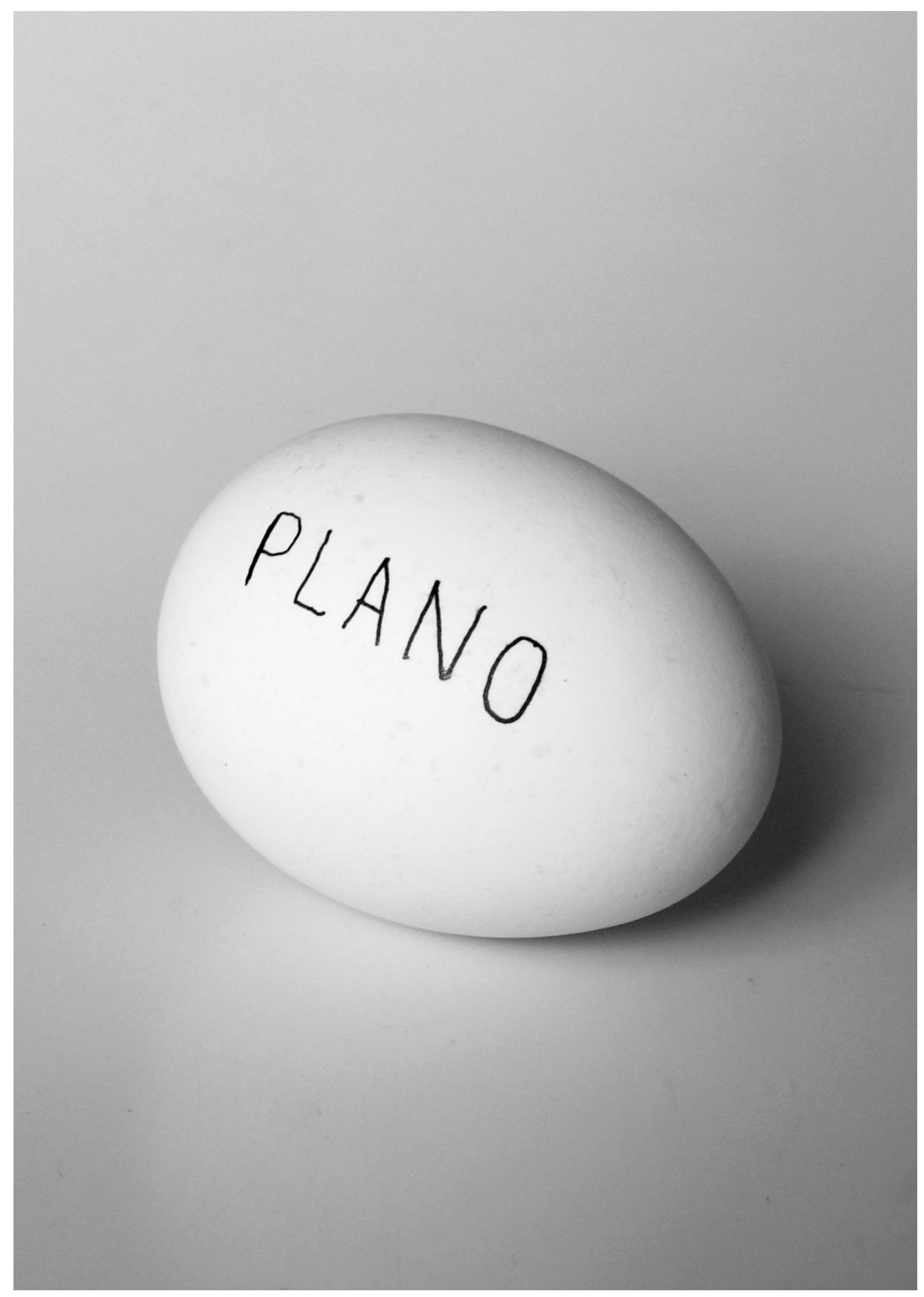

ovo - plano sobre plano - sobreposição. 


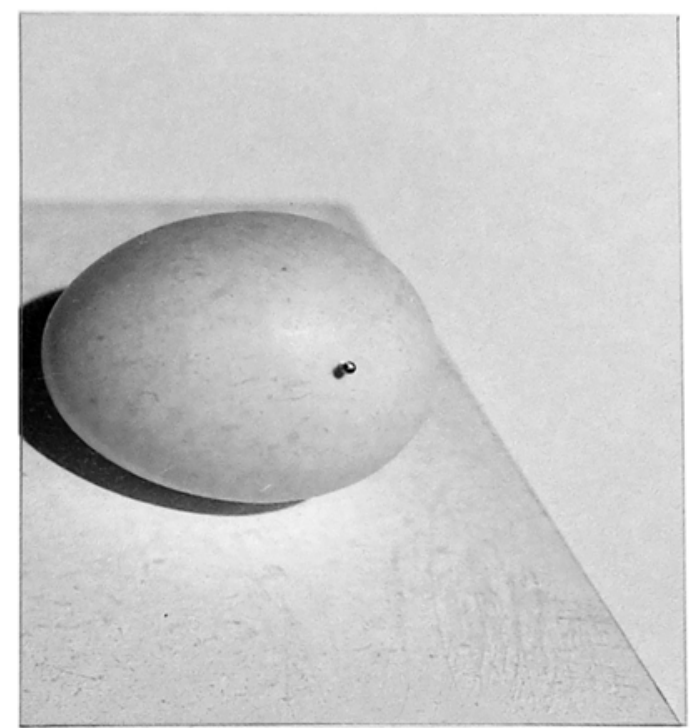

ponto sobre plano sobre plano - linha - alguma coisa para Morandi. 
$256 \mid$ ZETETIKÉ - FE/UNICAMP \& FEUFF - V. 23, N. 43 - JAN/JUN-2015

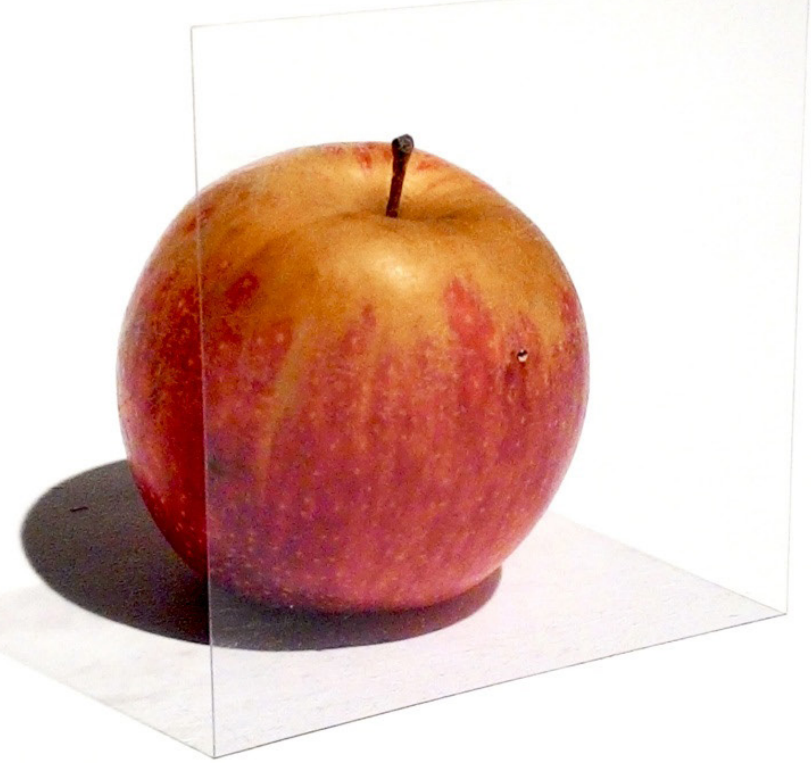

ainda a questão da pintura - plano, simetria e corte. 


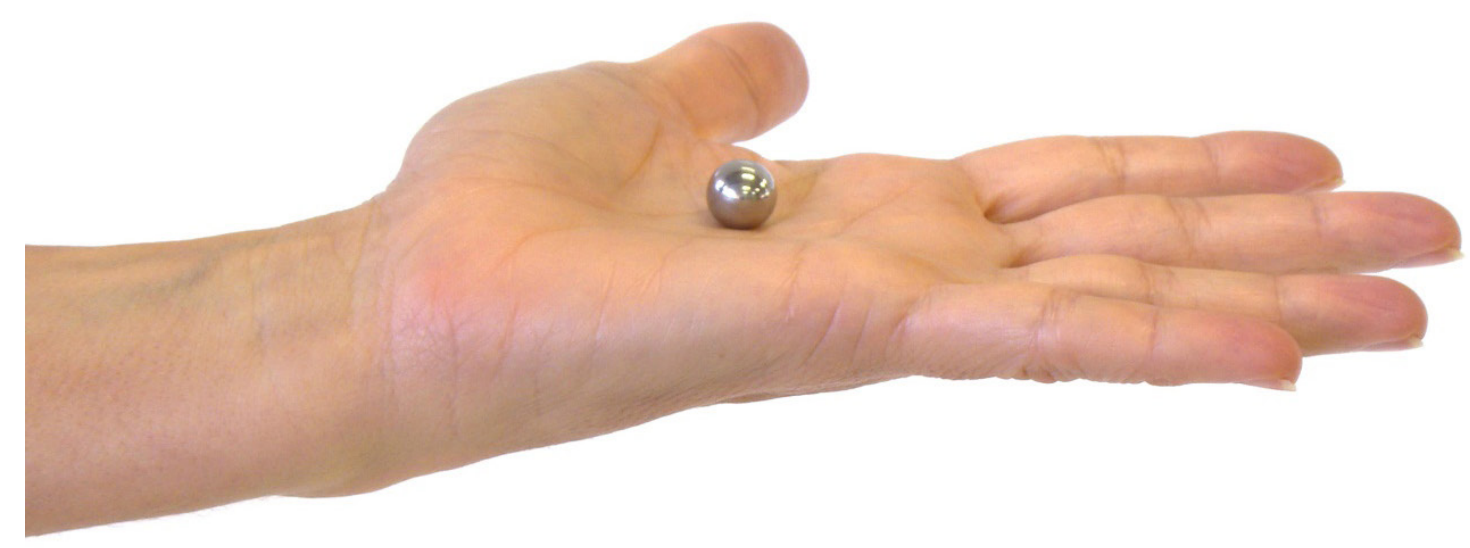

ideal - centro e simetria. 
258 | ZETETIKÉ - FE/UNICAMP \& FEUFF - V. 23, N. 43 - JAN/JUN-2015

algo instável - esfera de metal e disco de madeira. 


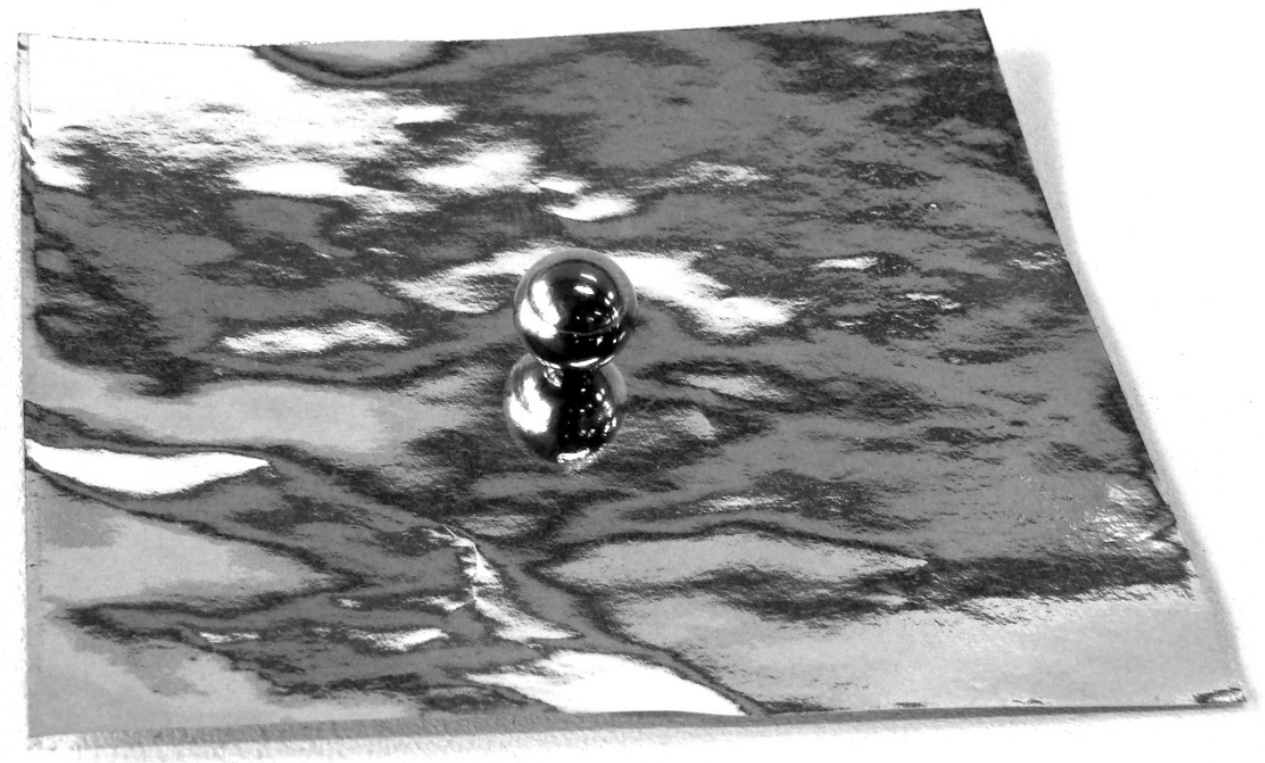

o problema dos limites - esfera cromada sobre superfície brilhante. 


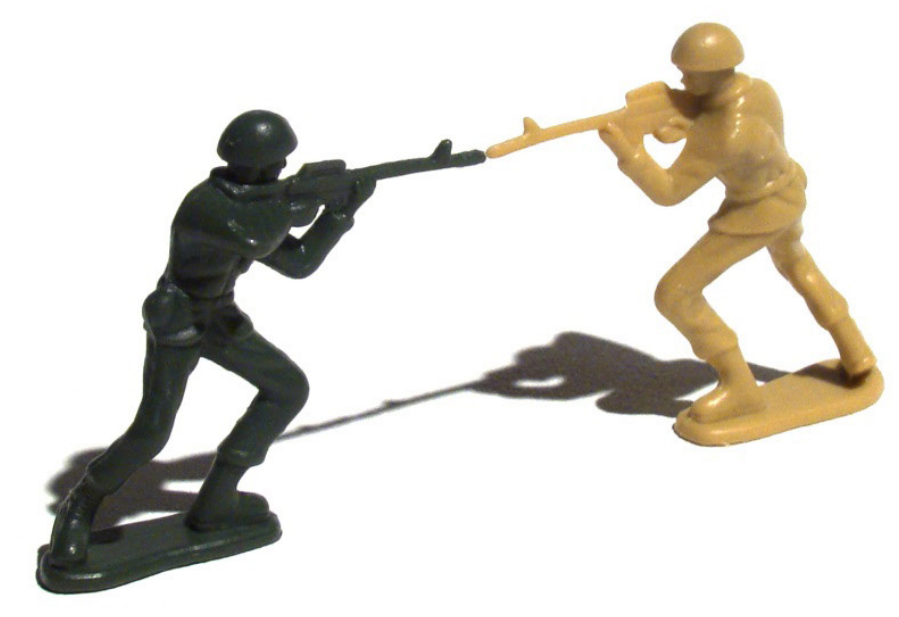

e ponto - só uma questão de cor. 
ZETETIKÉ - FE/UNICAMP \& FEUFF - V. 23, N. 43 - JAN/JUN-2015 261

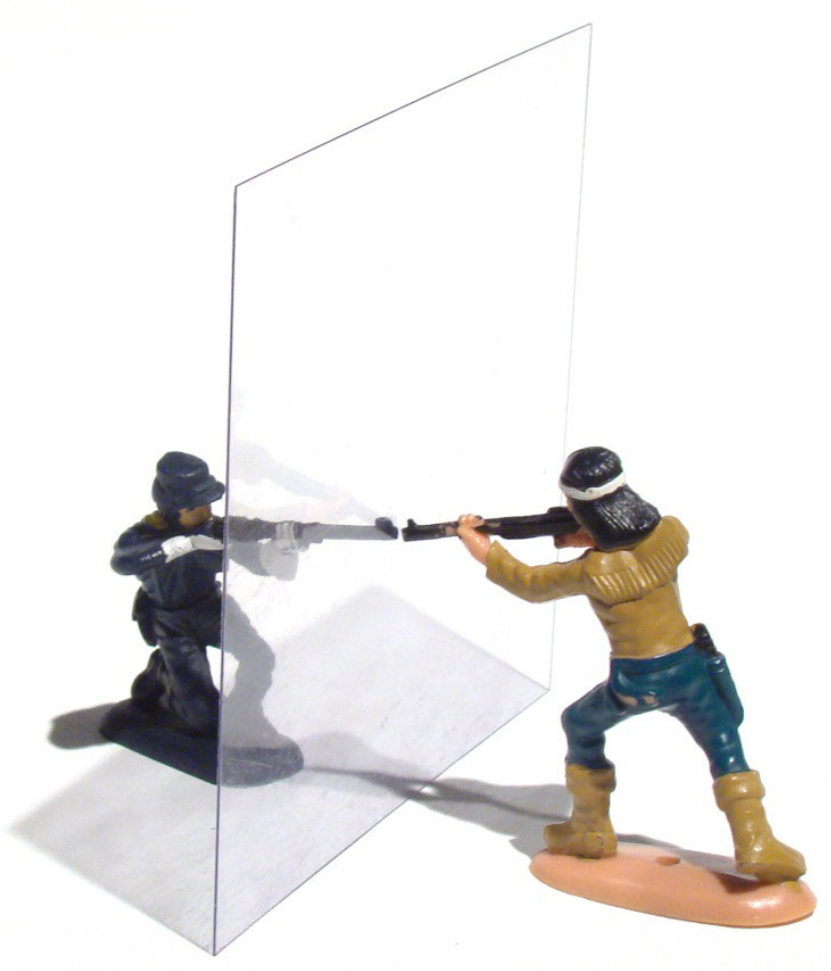

o plano - luz e sombra. 
$262 \mid$ ZETETIKÉ - FE/UNICAMP \& FEUFF - V. 23, N. 43 - JAN/JUN-2015

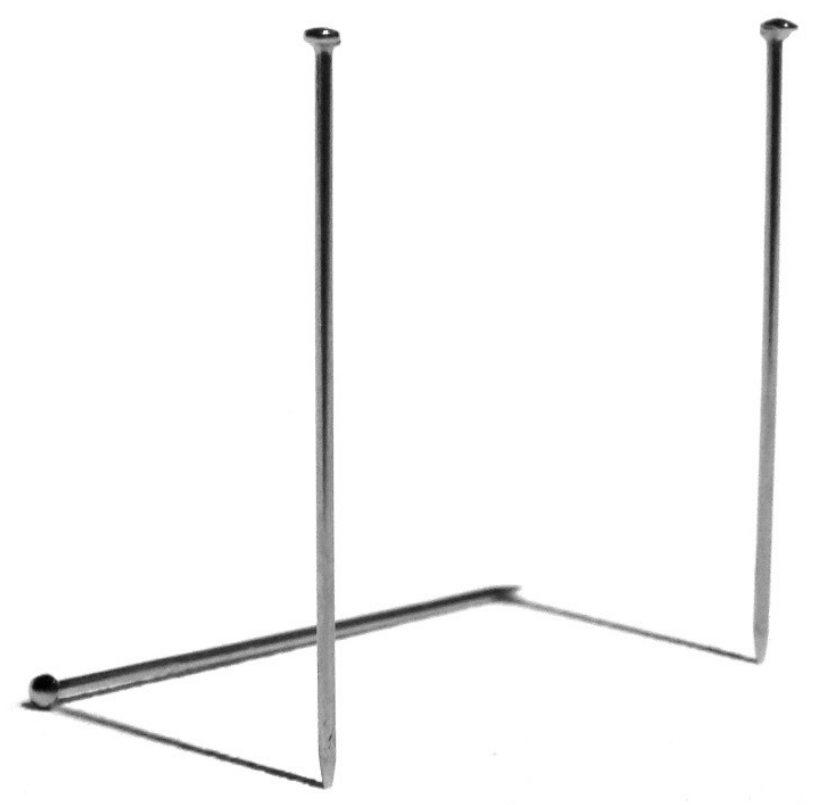

três alfinetes - ou cinco. 
ZETETIKÉ - FE/UNICAMP \& FEUFF - V. 23, N. 43 - JAN/JUN-2015 263

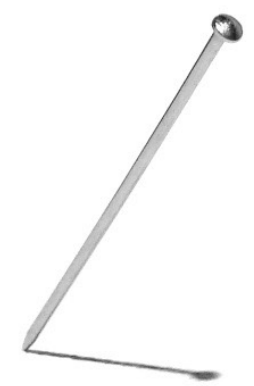

divisão - alfinete e sua sombra. 
$264 \mid$ ZETETIKÉ - FE/UNICAMP \& FEUFF - V. 23, N. 43 - JAN/JUN-2015

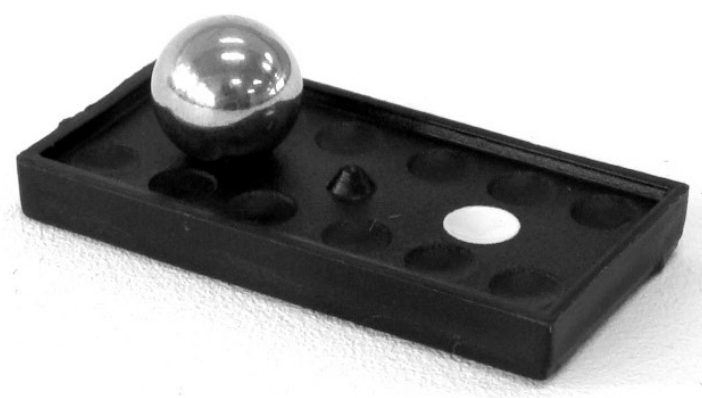

multiplicação - ou seus efeitos. 


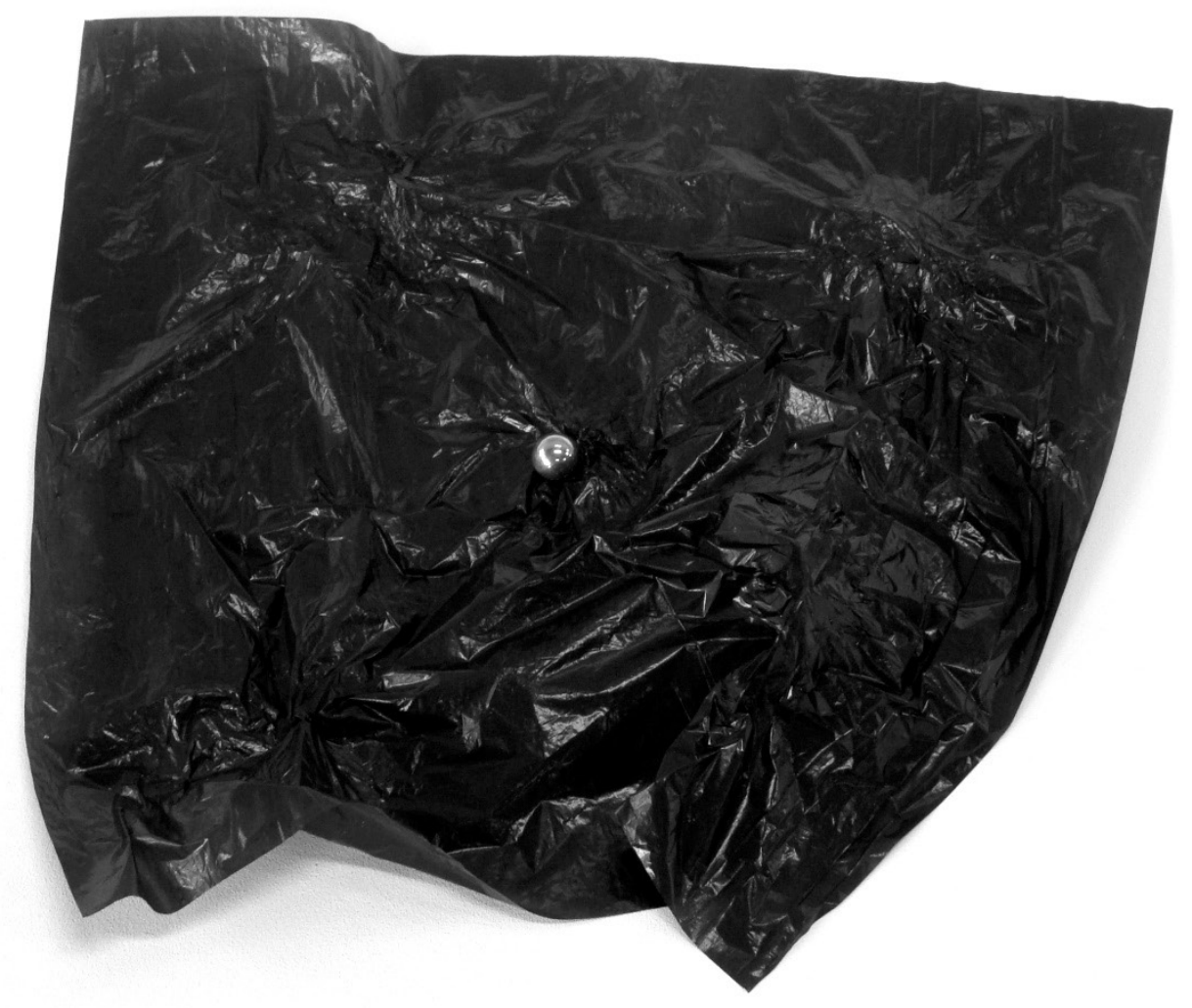

não é o ideal - esfera em superfície rugosa. 


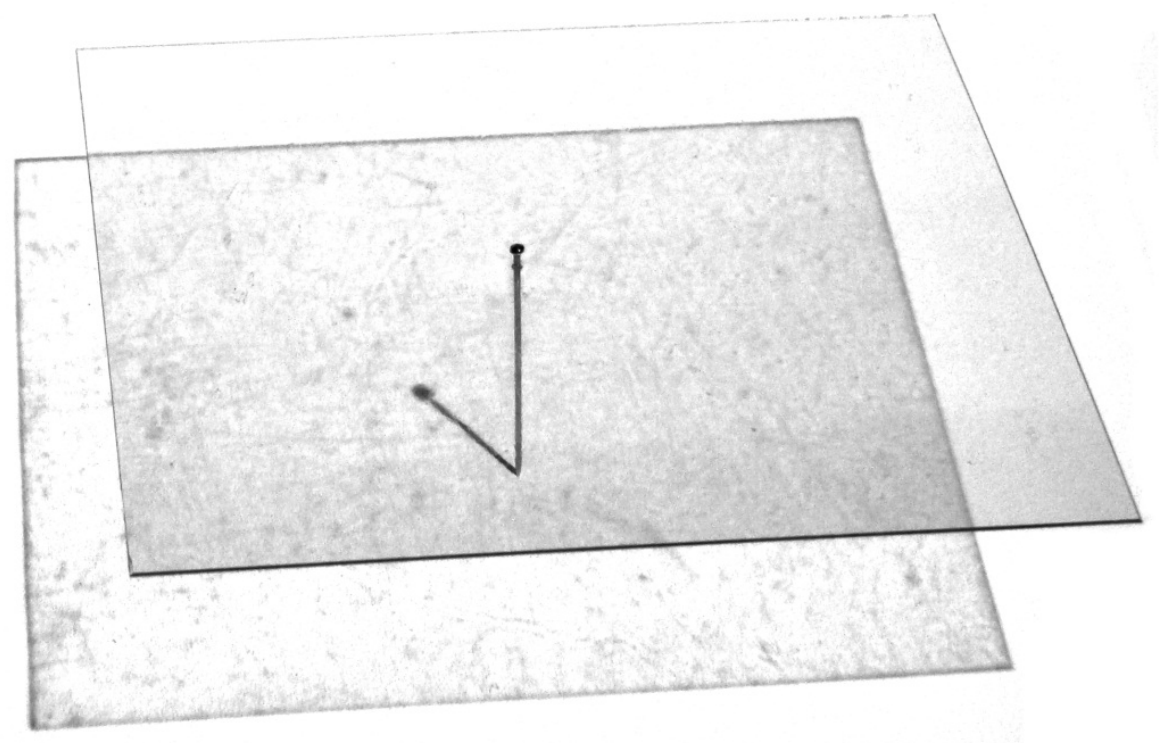

plano sobre plano - um pouco depois do meio dia. 
ZETETIKÉ - FE/UNICAMP \& FEUFF - V. 23, N. 43 - JAN/JUN-2015 267

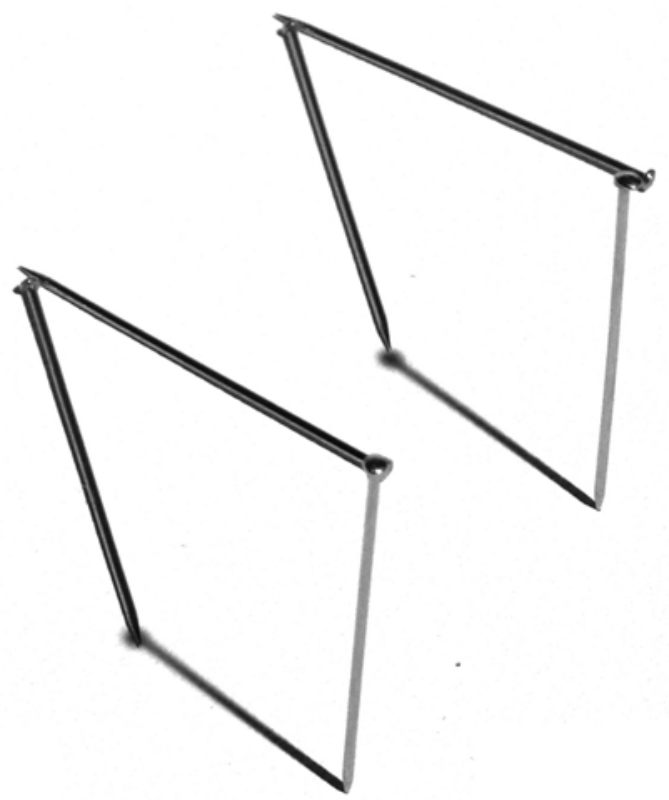

paralelismos - ou nem tudo aqui é plano. 


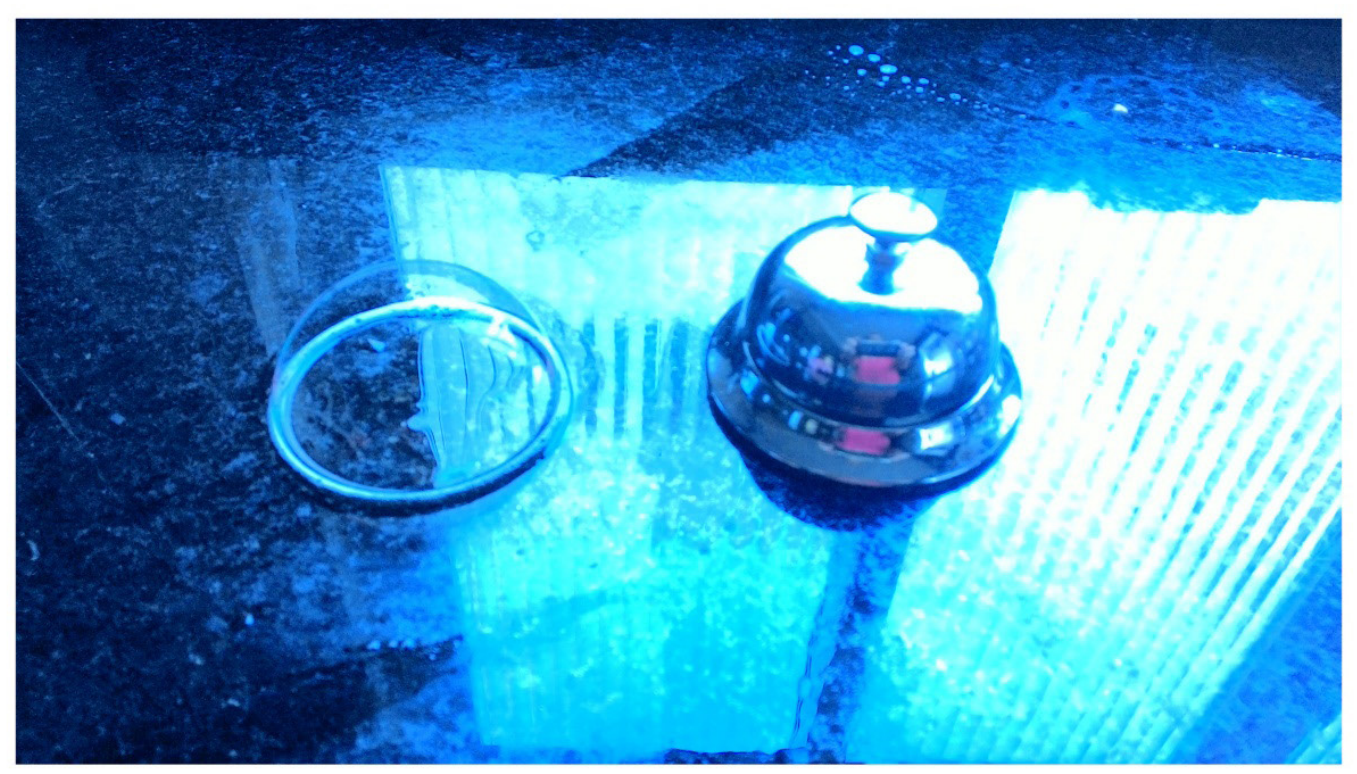

déjà vu - o efêmero e o nem tanto - espaço no tempo. 


\section{Ponto, pontos. Linha, linhas. Plano, planos.}

O ponto geométrico é um ser invisível [e indivisível]. Deve, portanto, ser definido como imaterial [sem dimensões]. Do ponto de vista material, o ponto campara-se ao Zero. Mas este zero esconde diferentes propriedades "humanas". Segundo a nossa concepção, este zero - o ponto geométrico - evoca o laconismo absoluto, ou seja, a maior retenção mas, no entanto fala, ao mesmo tempo é conexão entre aquilo que é e um outro, num sentido positivo. Assim, o ponto geométrico é, segundo nossa concepção, a última e única união do silêncio e da palavra. Eis por que o ponto geométrico encontrou a sua forma material em primeiro lugar na escrita - ele pertence à linguagem e significa silêncio (Kandinsky, 1997, p. 17).

O ponto faz parte do domínio dos hábitos arraigados em nós com sua ressonância tradicional, que é muda. A ressonância do silêncio, habitualmente associada ao ponto, é tão forte que suas outras propriedades ficam ensurdecidas por ela. Não ouvimos mais sua voz e somos cercados de silêncio. Somos mortalmente subjugados pelo "utilitário-útil" do ponto como silêncio. O hábito se torna aquilo que vela o som dos pontos. (Kandinsky, 1997, p. 18).

Ponto é aquilo de que nada é parte (Euclides, 2009, p. 97).

O ponto fala o silêncio.

[...] os pontos são para ele [o nômade] alternâncias num trajeto (Deleuze \& Guattari, 2012, p. 54).

Um trajeto está sempre entre dois pontos, mas o entre-dois tomou toda a consistência, e goza de uma autonomia bem como de uma direção próprias. (Deleuze \& Guattari, 2012, p. 53)

A linha geométrica é um ser invisível [mas não indivisível]. É o rastro do ponto em movimento, logo seu produto [ou seu efeito]. Ela nasceu do movimento - e isso pela aniquilação da imobilidade suprema do ponto. Produz-se aqui o salto do estático para o dinâmico. (Kandinsky, 1997, p. 49, 61)

E linha é comprimento sem largura. (Euclides, 2009, p. 97)

Do estático para o dinâmico... do silêncio para o som...

Linha: movimento, som, manifestação visual.

Linha: mapeamento do trajeto do ponto sobre a superfície: nega o silêncio visual do ponto.

[...] traçar a linha, ou, o que dá no mesmo, atravessar a linha, passar a linha, visto que ela só é traçada quando se ultrapassa a linha de separação. (Deleuze \& Guattari, 2012b, p. 89) 
A linha já não faz contorno, e passa entre as coisas, entre os pontos. (Deleuze \& Guattari, 2012b, p. 234)

[...] a linha não tem dimensão superior ao ponto, a superfície não tem dimensão superior à linha, nem o volume dimensão superior à superfície, mas há sempre um número de dimensão fracionária, anexato, ou que não para de crescer ou de decrescer com as partes. (Deleuze \& Guattari, 2012b, p. 237)

E superfície é aquilo que tem somente comprimento e largura. (Euclides, 2009, p. 97).

Superfície plana é a que está posta por igual com as retas sobre si mesma (Euclides, 2009, p. 97).

A superfície se destina a suportar a obra

O plano pode ser um princípio oculto, que dá a ver aquilo que se vê, a ouvir aquilo que se ouve..., etc., que faz a cada instante que o dado seja dado, sob tal estado, a tal momento. Mas ele próprio, o plano, não é dado. Ele é oculto por natureza. (Deleuze \& Guattari, 2012a, p. 54)

Por ora, seria preciso dizer simplesmente que existem dois tipos de viagem, que se distinguem segundo o papel respectivo do ponto, da linha e do espaço. [...] Viagem-árvore e viagem-rizoma? Mas nada coincide inteiramente, e além disso tudo se mistura, ou passa de um para outro. (Deleuze \& Guattari, 2012b, p. 202).

Plano de vida, plano de música, plano de escrita, é igual: um plano que não pode ser dado enquanto tal, que só pode ser inferido, em função das formas que desenvolve e dos sujeitos que forma, pois ele é para essas formas e esses sujeitos. (Deleuze \& Guattari, 2012a, p. 55).

A forma, no sentido estrito da palavra, não é nada mais que a delimitação de uma superfície por outra superfície. Essa é a definição de seu caráter exterior. Mas toda coisa exterior também encerra, necessariamente, um elemento interior (segundo os casos, mais fraca ou mais fortemente). Portanto cada forma também possui um conteúdo interior. A forma é a manifestação exterior desse conteúdo. Tal é a definição do seu caráter interior. [...] Em toda arte, a derradeira expressão abstrata é o número. (Kandinsky, 1996, p. 76, 121).

Ali onde a visão é próxima, o espaço não é visual, ou melhor, o próprio olho tem uma função háptica e não óptica: nenhuma linha separa a terra e o céu, que são da mesma substância; não há horizonte, nem fundo, nem perspectiva, nem limite, nem contorno ou forma, nem centro; não há distância intermediária, ou qualquer distância é intermediária. (Deleuze \& Guattari, 2012b. p. 219). 


\section{matemática e arte e educação}

Um convite: produzir junto ao tema "matemática, arte e educação".

Convite que se dobra, desdobra e redobra em questões: o que produzir, ou o que se produz, quando se atritam matemática e arte e educação?

Talvez se produzam faíscas, ou lascas, capazes de gerar incêndios ou cortes ou simplesmente pontas que podem "cutucar", espetar matemática, arte e educação.

Um convite que vem de Waltércio Caldas...

Um convite a Kandinsky, que já havia convidado a matemática (geometria) para compor com a arte (pintura), e a Euclides, ou mais especificamente à geometria dita euclidiana: ponto, linha, plano.-

Mais uma dobra: Que matemática? Que arte? Que educação? Que pontos? Que linhas? Que planos?

Matemática em estado de arte, faiscando, cutucando uma educação em estado de arte. Ou o contrário?

Atritando, as coisas se multiplicam ao mesmo tempo em que multiplicando se atritam ainda mais.

Aqui um convite ao efêmero, olhar mais uma vez para o cotidiano, dedicar-se ao banal, procurando pela arte, pela matemática, pela educação em algum estado ainda "bruto", menos teórico, talvez um "devir": produzir arte em matemática? Produzir arte com matemática? Produzir com arte em matemática? Produzir arte em estado de arte; matemática em estado de matemática; matemática em estado de arte; educação em estado de educação, de arte, de matemática...

Olhar para o entorno imediato procurando enxergar nos objetos, em presenças tão pequenas, as relações de atrito a partir das quais há o desejo de produzir. Entretanto, objetos também convidam, eles mesmos, também ao olhar, à presença, ao desejo, ao atrito...

É que não se trata tanto dos objetos, mas de algo em alguma situação específica, meio incerta de fato, mas quase localizados, num ali meio imponderável, que nos tira também do lugar. Em todo caso o lugar aqui é aparentemente planificado pelo registro fotográfico impresso nestas páginas: pontos e linhas sobre planos. Um ponto, pontos. Uma linha, linhas. Um plano, planos.

Sucessão de planos, produção de imagens. Mas não é cinema.

A coisa se dá ora pela relação destes elementos "geométricos" com os objetos, ora os objetos que produzem uma "geometria" nas suas relações. As ordens e os fatores se alteram a todo instante.

Aliás, a palavra é INSTANTE. O momento fugaz em que uma bola de sabão se transforma num círculo ou em uma semiesfera. 
Convite para colocar(-se) mais uma vez em convite, em encontros com aquilo que as imagens lançam.-

Um convite que se expande...

Não se trata mais de saber se são olhares matemáticos, artísticos, educativos. Nem mesmo trata-se de olhar, ou de saber olhar. A questão é pensar que matemáticas, que artes, que educações se dão com olhos, com bocas, com peles, com imagens, com objetos, com luzes e sombras, com efemeridades, com proposições, com cores e sem elas... entre pontos, linhas e planos que por ai estão.

\section{Convidados:}

Caldas, W. (2007). Manual da Ciência Popular. 2a ed. São Paulo: Cosac Naify.

Euclides. Os elementos.Tradução: Irineu Bicudo. São Paulo: Unesp, 2009.

Kandinsky, W. (1996). Do espiritual na arte e na pintura em particular. São Paulo: Martins Fontes.

Kandinsky, W. (1997). Ponto e linha sobre plano. São Paulo: Martins Fontes.

Deleuze, G. \& Guattari, F. (2012a). Mil Platos: capitalismo e esquizofrenia 2.Vol.4. São Paulo: Editora 34.

Deleuze, G. \& Guattari, F. (2012b). Mil Platos: capitalismo e esquizofrenia 2.Vol.5. São Paulo: Editora 34.

Zourabichvili, François. (2004). O Vocabulário de Deleuze. Rio de Janeiro: Relume Dumará.versão digital ifch-unicamp. Disponível em http://claudioulpiano.org. br.s87743.gridserver.com/wpcontent/uploads/2010/05/deleuze-vocabulario-francois-zourabichvili1.pdf

Submetido em: 14/06/2015

Aprovado em: 30/08/2015 